\title{
Stability Evaluation on Surrounding Rocks of Underground Powerhouse Based on Microseismic Monitoring
}

\author{
Feng Dai, ${ }^{1}$ Biao Li, ${ }^{1}$ Nuwen $\mathrm{Xu},{ }^{1}$ Yongguo $\mathrm{Zhu}^{2}$ and Peiwei Xiao ${ }^{2}$ \\ ${ }^{1}$ State Key Laboratory of Hydraulics and Mountain River Engineering, Sichuan University, Chengdu 610065, China \\ ${ }^{2}$ China Guodian Dadu River Houziyan Hydropower Development Co., Ltd., Kangding 626005, China \\ Correspondence should be addressed to Nuwen Xu; xunuwen@scu.edu.cn
}

Received 14 December 2014; Accepted 17 March 2015

Academic Editor: Tai Thai

Copyright (c) 2015 Feng Dai et al. This is an open access article distributed under the Creative Commons Attribution License, which permits unrestricted use, distribution, and reproduction in any medium, provided the original work is properly cited.

\begin{abstract}
To study the stability of underground powerhouse at Houziyan hydropower station during excavation, a microseismic monitoring system is adopted. Based on the space-time distribution characteristics of microseismic events during excavation of the main powerhouse, the correlation between microseismic events and blasting construction is established; and the microseismic clustering areas of the underground powerhouse are identified and delineated. The FLAC3D code is used to simulate the deformation of main powerhouse. The simulated deformation characteristics are consistent with that recorded by microseismic monitoring. Finally, the correlation between the macroscopic deformation of surrounding rock mass and microseismic activities is also revealed. The results show that multiple faults between $1 \#$ and 3\# bus tunnels are activated during excavation of floors V and VI of the main powerhouse. The comprehensive method combining microseismic monitoring with numerical simulation as well as routine monitoring can provide an effective way to evaluate the surrounding rock mass stability of underground caverns.
\end{abstract}

\section{Introduction}

High mountains and steep roads are distributed in the southwest region of China and therefore many large-scale hydropower projects cannot avoid constructing underground caverns. Usually, the prominent problems of the underground caverns such as the complex geological conditions, large burial depth, high stress, and strong construction disturbance seriously threaten the stability of surrounding rock mass during excavation. As a result, security incidents caused by excavation are often encountered. Specifically, on August 23, 2013, a landslide occurred during excavation of the spillway tunnel on the left bank of Houziyan hydropower station, killing 5 people; on November 28, 2009, an extremely strong rock burst occurred on the construction drainage tunnel of Jinping-II hydropower station, destroying the entire support system, seriously damaging TBM equipment, and killing 7 people [1]; on December 16, 2008, a landslide occurred on the upstream side of the vault part due to blasting excavation on the upstream side of the main powerhouse in Dagangshan hydropower station, with the landslide amount reaching
$2968 \mathrm{~m}^{3}$ [2]. The stability analysis on underground caverns during excavation can not only prevent the occurrence of security incidents but also play a significant role in subsequent construction and selection of support parameters.

Traditional monitoring (such as the multipoint displacement meter, bolt stress meter, and geophysical prospecting instrument) [3,4] and numerical simulation [5-7] are commonly used for evaluating the stability of the underground caverns during excavation. Most traditional monitoring methods determine the rock stability depending on the deformation characteristics or mechanical parameter assessment at the monitoring point (line or area). However, the monitoring data has certain limitations in space, and the minor failure of surrounding rock before deformations can hardly be monitored. The numerical simulation method is simple and convenient, quantitatively showing parameters such as the stress and strain of each part of surrounding rock and evaluating the potential risk area of surrounding rock through series of numerical analysis and calculations. However, it cannot completely consider the real mechanical parameters and stress status of rocks, and the simulation 


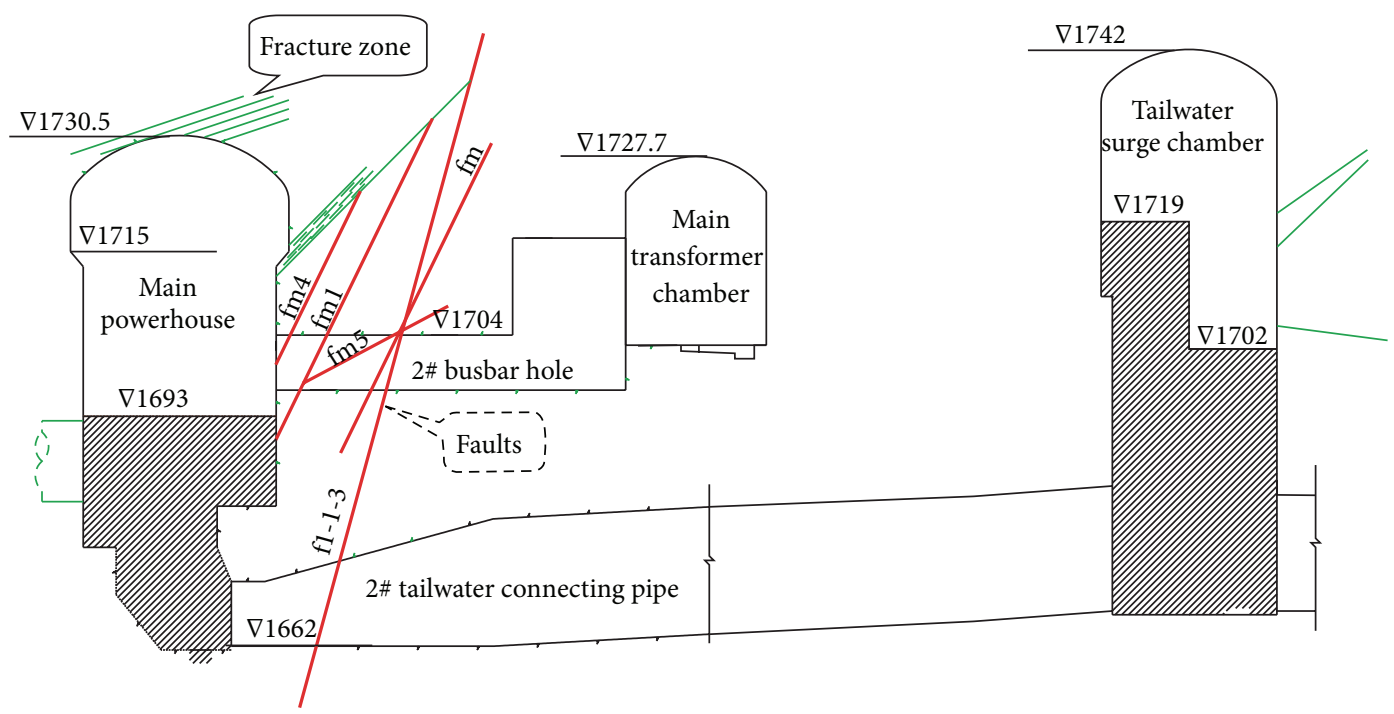

FIGURE 1: Geological profile along the axis of 2\# busbar tunnel.

results may be quite different from the actual failure area. As a new monitoring method, microseismic monitoring allows receiving the microfracture signal (microseismic event) of internal rock before rock macroscopic deformations, conducting back analysis on the microfracture occurrence time, position, and magnitude (i.e., time, space, and intensity) as well as deducing the rock failure degree and forecasting the development trend of the deformation and displacement by using the $3 \mathrm{D}$ distribution density of the rock microfracture [8]. In recent years, the microseismic monitoring technology has been gradually promoted and applied to the hydropower field in China [9-11].

In this paper, we conducted extensive studies based on previous researches [12]. In particular, we delineated the potential instability and failure areas and described their formation during excavation of underground cavern surrounding rock, based on geological materials, field construction, and the space-time distribution characteristics of microseismic events during excavation of floors $\mathrm{V}$ and VI of the main powerhouse. Moreover, we compared simulation results with monitoring data of the multiple position extensometers and comprehensively evaluated the stability of the underground powerhouse during excavation. The research results can provide a basis for support parameters and subsequent excavation of the main powerhouse and important reference for similar underground engineering practices.

\section{Engineering Background}

2.1. Overview of Geological Conditions. For details about the cavern layout of the underground powerhouse system and overview of Houziyan hydropower station, refer to the paper of $\mathrm{Li}$ et al. [12]. The underground powerhouse area has complex geological conditions. Figure 1 shows the section of $2 \#$ bus tunnel in the axial direction. Multiple interlaced secondary faults develop on the small section of the bus tunnel, inclining to the free face of the downstream side wall in the main powerhouse. Many joints and cracks exist in some area of the downstream side wall of the main powerhouse vault and tailrace surge chamber. Surrounding rocks mainly consist of class III limestone and dolomitic limestone. The attitude of stratum is $\mathrm{N} 50^{\circ} \sim 70^{\circ} \mathrm{E} / \mathrm{NW} \angle 25^{\circ} \sim 50^{\circ}$. The rock is generally complete and compact with uniaxial tensile strengths ranging from 60 to $100 \mathrm{MPa}$.

The unloading and failure problems of surrounding rocks are prominent during excavation of the main powerhouse, and the downstream side wall frequently shows loosening, cracking, and side falling phenomena. To identify and delineate the potential instability area of surrounding rocks in advance and take effective support measures to avoid dangerous accidents, the Canadian ESG monitoring equipment is adopted to conduct analysis on surrounding rock stability during excavation of the main powerhouse $[2,4]$.

2.2. Microseismic Monitoring. The microseism refers to the quake in form of seismic wave generated as rocks crack in a local area due to certain causes (such as engineering excavation) [8]. A transducer is installed within a certain area of rocks to receive seismic wave information; the processing software is adopted to process and analyze seismic wave information; then hypocenter information such as the microseismic event occurrence time, hypocenter position, moment magnitude, and released energy can be calculated. Parameter information such as the microseismic event density, seismic moment, and released energy is used to reveal the deformation and failure evolution laws of surrounding rock as well as to predict and evaluate rock stability.

The ESG microseismic monitoring system is mainly composed of the acceleration transducer, Paladin digital signal acquisition system, and Hyperion digital signal processing system. The microseismic monitoring area in the underground cavern groups of Houziyan hydropower station centers on surrounding rocks of the vault as well as upstream 
TABLE 1: Mechanical parameters of rock mass in the underground powerhouse.

\begin{tabular}{lcccccc}
\hline Rock mass & $\begin{array}{c}\text { Deformation } \\
\text { modulus/GPa }\end{array}$ & Poisson's ratio & Cohesion/MPa & $\begin{array}{c}\text { Friction } \\
\text { coefficient }\end{array}$ & $\begin{array}{c}\text { Tensile } \\
\text { strength/MPa }\end{array}$ & $\begin{array}{c}\text { Unit } \\
\text { weight } /\left(\mathrm{kN} \cdot \mathrm{m}^{-3}\right)\end{array}$ \\
\hline III $_{1}$ & 25 & 0.25 & 15 & 1.2 & 5.5 & 2800 \\
Faults & 4 & 0.35 & 0.5 & 0.45 & 0.0 & 2000 \\
\hline
\end{tabular}

Total events: 288 North: $-100.00 \sim 250.00 \mathrm{~m}$ East: $-100.00 \sim 200.00 \mathrm{~m}$

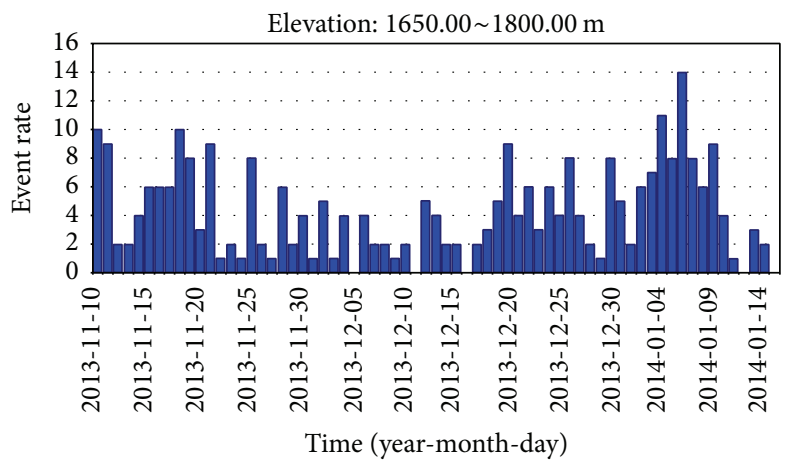

FIGURE 2: Temporal distribution of microseismic events.

and downstream side walls of the main powerhouse and covers surrounding rock of some pipelines including the pressure pipeline and pipelines on the upstream side of the transformer chamber and tailrace surge chamber. Other details about the transducer spatial arrangement, system performance, parameter settings, and system topology of the microseismic monitoring system can be referred to Li et al. [12].

\section{Microseismic Activity Characteristics and Stability Evaluation during Excavation of the Underground Powerhouse}

3.1. Analysis on the Microseismic Activity Frequency during Excavation. In early November 2013, during the excavation of floors V and VI (EL. 1693 1680 m) of the main powerhouse of the Houziyan hydropower station, system support for the transformer chamber and bus tunnel lining were completed. By January 15, 2014, excavation of floors V and VI of the main powerhouse had been completed. During excavation of the main powerhouse, from November 10, 2013, to January 15, 2014, 288 microseismic events were obtained within an affective range after waveform adjustment and interference event identification and elimination.

Figure 2 shows the occurrence time and activity frequency of microseismic events. From November 10 to 21, 2013, and from late December 2013 to early January 2014, the microseismic events frequently occurred. Analysis on the blasting construction revealed that blasting construction of the main powerhouse frequently occurred during the preceding two periods and the excavation-induced strong unloading greatly disturbed rocks and caused amounts of rock microfractures to initiate and develop. In particular, two events with the highest activity frequency occurred on January 4 and 6, that is, 11 times/day and 14 times/day, respectively. According to Table 1 , there were fewer main powerhouse blasting events from January 4 to 10 but the overall frequency of microseismic events reached the highest. Analyses are conducted based on the blasting position and geological conditions of the main powerhouse. Multiple fault and soft structural planes grow in surrounding rocks on the downstream side of the main powerhouse. On December 28 and 29 and on January 2 and 5, strong blasting occurred many times on the second half of the main powerhouse. The faults near the blasting position were activated. From January 4 to 10 , surrounding rock was still in the stress adjustment period and the soft structural plane was likely to show stress concentration, inducing a large number of microfractures. The time distribution of microseismic events reveals well the impact of dynamic construction on surrounding rock failure. Microseismic events tend to be abundant during the frequent blasting excavation period. Surrounding rock failure caused by blasting excavation includes the coupling effect of blasting impact load and rock dynamic unloading. The stress wave caused by blasting directly acts on side walls around the blasting point, resulting in failure of surrounding rock cracking on the free face, causing certain disturbance to deep rock and inducing the surrounding rock failure such as the rock microfracture and even rock burst [13]. The surrounding rock failure caused by dynamic unloading plays a leading role [14]. Excavation-induced unloading causes new free faces, breaks the initial stress balance, redistributes stress adjustment, and causes stress and energy concentration on local surrounding rock and even rock microfractures after a certain degree of stress and energy concentration.

3.2. Identification Method of the Potential Instability Area in the Underground Powerhouse Based on Microseismic Monitoring. The spatial distribution of microseismic events during excavation of floors V and VI of the main powerhouse is shown in Figure 3. The sphere refers to the microseismic event, sphere size refers to energy, and different colors refer to the moment magnitude.

According to Figure 3, microseismic events are mainly distributed between 1\# and 3\# bus tunnels, forming a band from the small section vault of the bus tunnel to the downstream side of the main powerhouse. After excavation of floors V and VI of the main powerhouse, surrounding rocks between bus tunnels show multiple free faces such as the powerhouse downstream side wall face, bus tunnel face, and transformer chamber upstream side wall face. Moreover, the original stress balance is broken and stress adjustment is redistributed. The initial triaxial stress status 


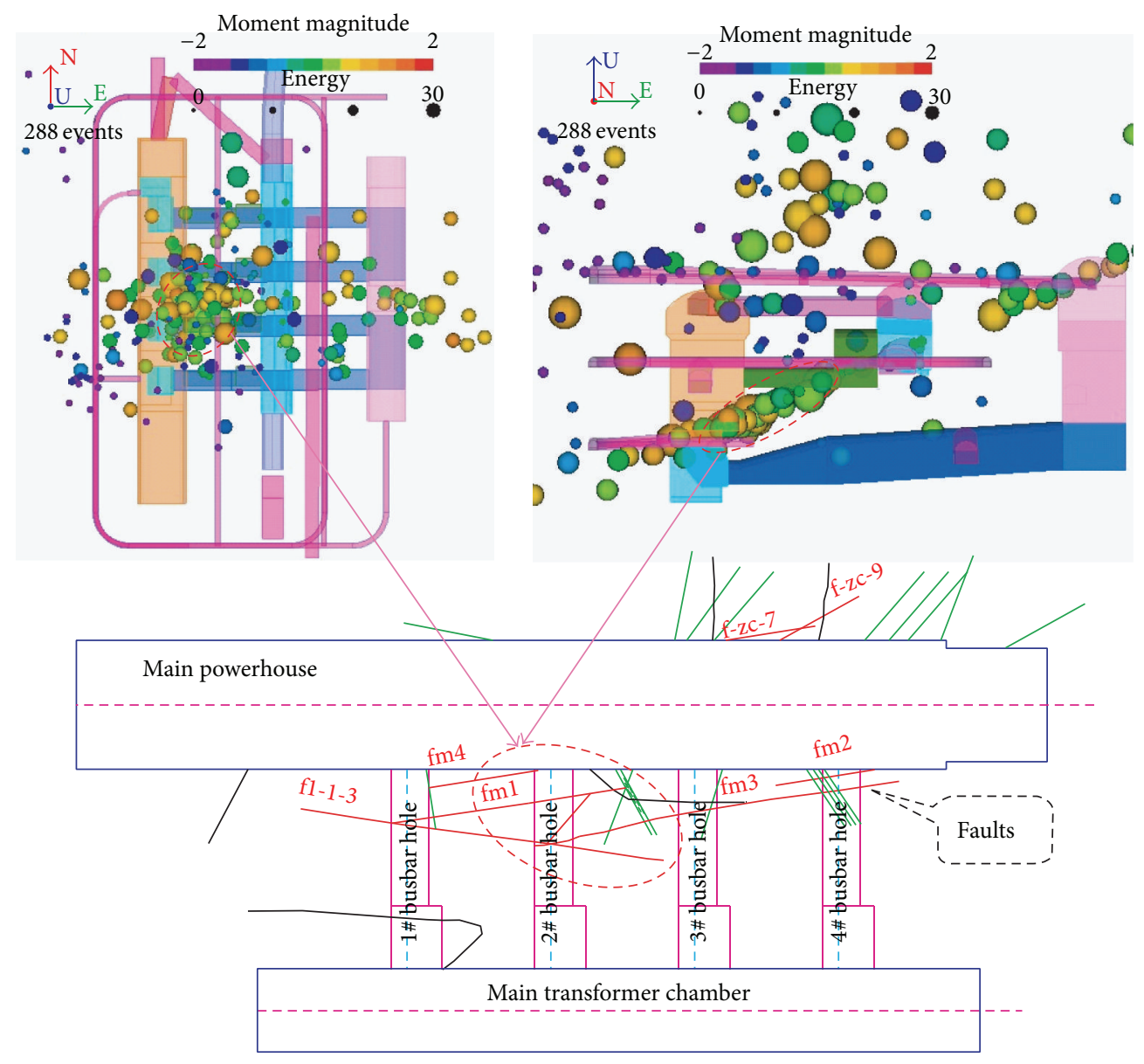

FIGURE 3: Relationship chart between spatial distribution of microseismic events and geological condition.

changed to the biaxial and even uniaxial stress status; and the stress concentrates on the local position (high stress and high stress difference areas such as the soft structural plane) [1]. According to the geological section at an elevation of $1704.85 \mathrm{~m}$ (small section vault of the bus tunnel) in Figure 3, the change of the stress status causes the occurrence of a large number of rock microfractures near the soft structural plane such as f1-1-3, fml, and fm4. The elastic energy accumulates and is released until a new stable stress balance status is formed [15-17].

Figure 4 shows the cloud chart of microseismic events, intuitively revealing the failure status of surrounding rock between $1 \#$ and $3 \#$ bus tunnels of the underground powerhouse, which agrees well with the spatial aggregation characteristics of microseismic events. Constant excavation of the lower rock of the powerhouse causes some fault footwall to be exposed, degrades mechanical parameters of rocks in the excavation failure area, and possibly results in the potential instability area controlled by the fault. Figure 5 shows multiple cracks discovered in 2\# bus tunnel during excavation. It is thus recommended to increase the number of anchor ropes or take other deep support measures to prevent local instability and failure of surrounding rock.

\section{Comparative Analysis on Numerical Simulation and Microseismic Monitoring Results of Underground Powerhouse Stability}

The FLAC3D code [18] is used to simulate the stability of a cross section (stake: $0+70 \mathrm{~m}$ ) at the main powerhouse (between 2\# and 3\# bus tunnels) subjected to excavation. The model considers the impact of faults including f1-1-3, fml, and fm4. The Mohr-Coulomb yielding criteria are adopted. The numerical model is shown in Figure 6 and the surrounding rock mechanical parameters are tabulated in Table 1.

Figures 7 and 8 show the displacement contour maps after excavation of floors IV and VI of the main powerhouse, respectively. It can be seen that during excavation of floors $\mathrm{V}$ and VI, deformations increase obviously, especially the surrounding rocks in the fault-controlled area near the main powerhouse downstream side wall; the displacement increases approximatly $15 \mathrm{~mm}$, with the total deformation reaching about $30 \mathrm{~mm}$. The largest deformation of the surrounding rocks appears at the border of the bottom plate and downstream sidewall. The excavation-induced unloading greatly disturbs the fault area. Meanwhile, it causes some fault footwall to be exposed and results in fault deformation near 


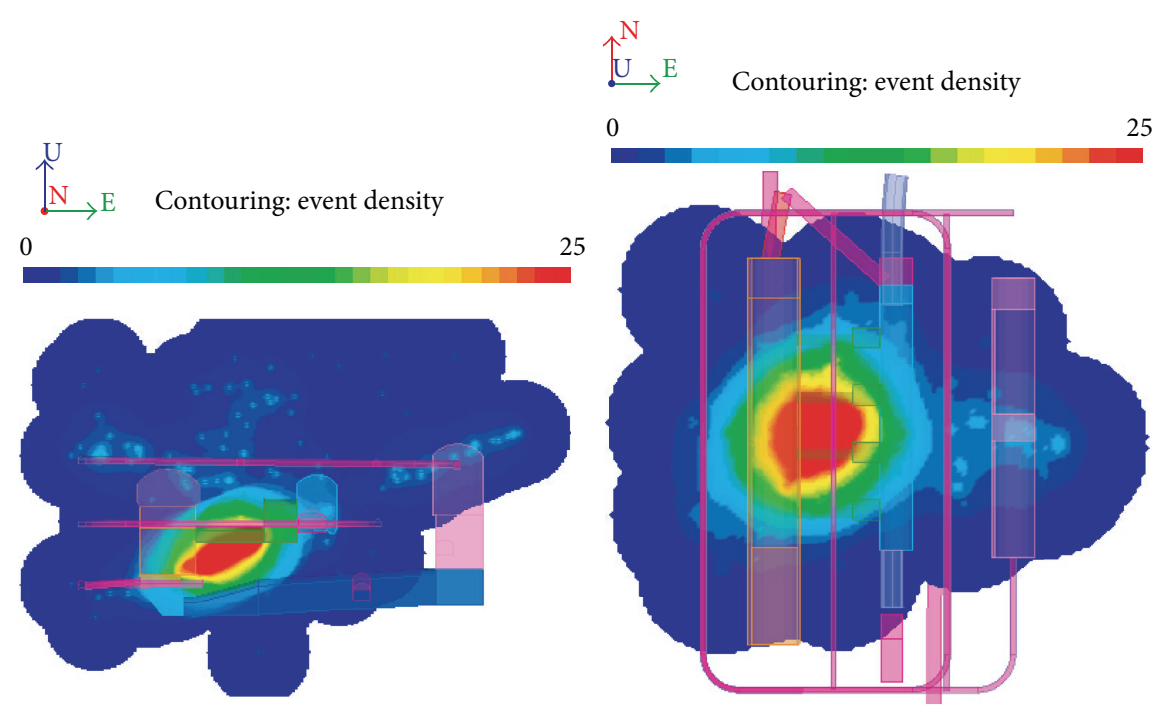

FIgURE 4: Density contour of microseismic events.

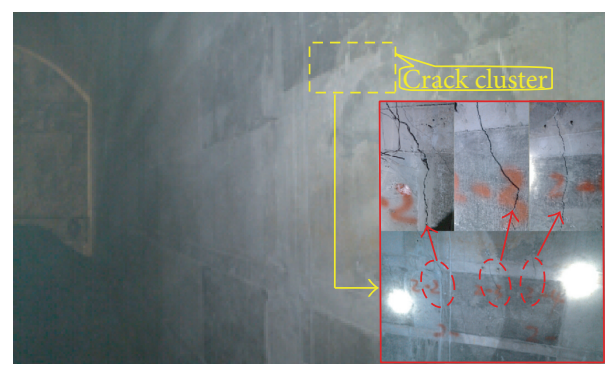

Figure 5: Cracks in the 2\# busbar tunnel.

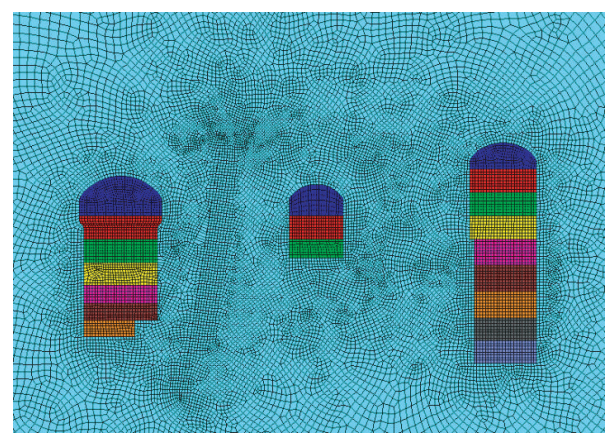

FIgURE 6: Numerical simulation model.

the surface and stress concentration in multiple places, which is delineated as the potential instability area of surrounding rock.

Figures 9(a) and 9(b) illustrate the contours of the maximum and minimum principal stress after excavation of floor VI of the main powerhouse, respectively, and the positive value represents tensile stress while the negative value represents compressive stress. The maximum principal stress concentration mainly occurred in the fault-controlled area near the downstream sidewall of the main powerhouse. Obvious stress concentration ccurred at the boundaries of

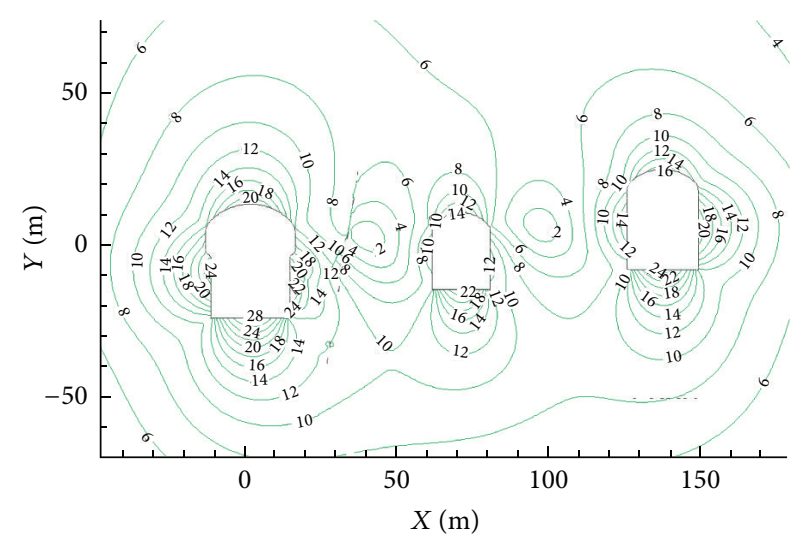

FIGURE 7: Contour of displacement after IV level excavation (unit: $\mathrm{mm})$.

the bottom plates and the sidewalls of the three main caverns. At the boundary of the bottom plate and downstream sidewall of the main powerhouse, the maximum principal stress reaches approximately $-100 \mathrm{MPa}$, which is in good agreement with the deformation characteristics. The value of the minimum principal stress near the main powerhouse downstream sidewall is relatively small. Especially in the fault-controlled area and around the excavation face, the minimum principal stress equals zero, which tends to induce more microseismic events.

Figure 10 shows the seismic deformation contour of the cross section (stake: $0+70 \mathrm{~m}$ ) in the main powerhouse revealed by microseismic events. The lighter the color is, the larger the deformation is. The major deformation area caused by excavation of floors V and VI of the main powerhouse is inclined to the downstream sidewall of the main powerhouse along the fault face direction and the largest seismic deformation concentrates at the boundary of powerhouse excavation floor and downstream sidewall. It can be seen 


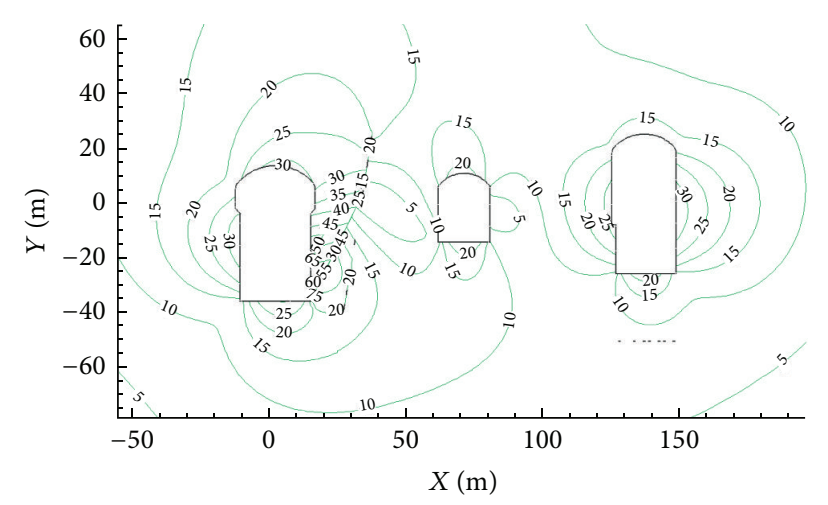

FIGURE 8: Contour of displacement after VI level excavation (unit: $\mathrm{mm}$ ).

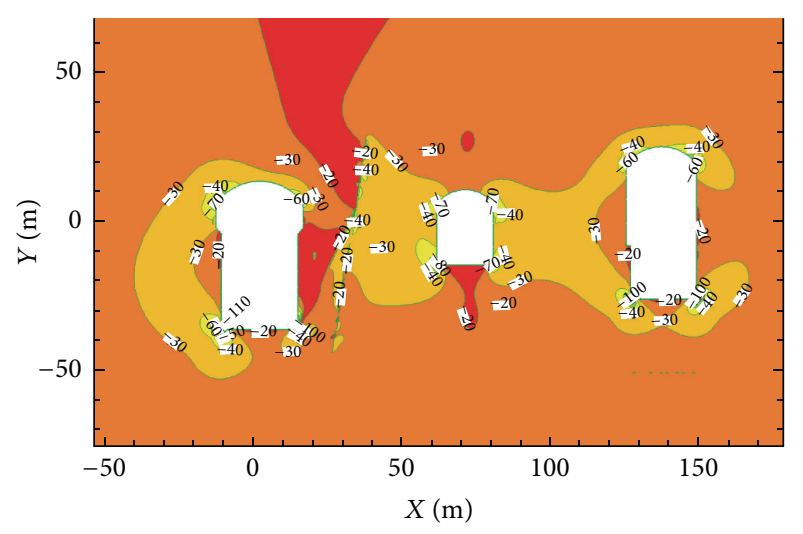

(a)

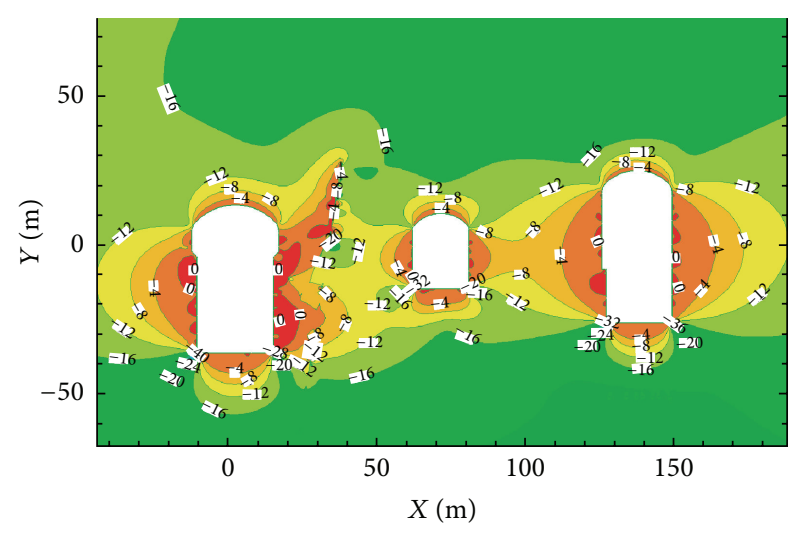

(b)

FIGURE 9: Contour of principal stresses after VI level excavation (unit: MPa). (a) The maximum principal stress contour. (b) The minimum principal stress contour.

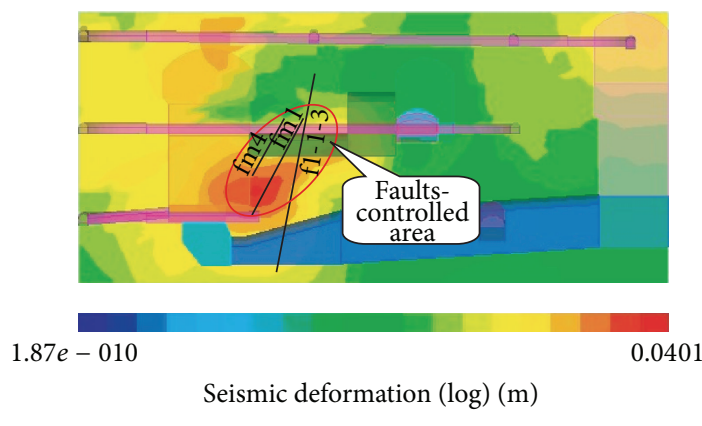

Figure 10: Contour of seismic deformation.

that the numerical simulation results are consistent with the characteristics of microseismic activities. The surrounding rock deformation of the underground powerhouse is mainly controlled by the faults, indicating that the faults and soft structural planes are one of the main factors affecting surrounding rock mass stability of the underground powerhouse subjected to excavation.

\section{Relation between Surrounding Rock Deformation and Microseismic Activities of the Underground Powerhouse}

5.1. Routine Monitoring Description. The routine monitoring methods of the underground powerhouse include the multiple position extensometer, bolt stress meter, anchorage dynamometer, and joint meter. During initial powerhouse construction, routine monitoring provides a reliable basis for stability analysis. Based on the data characteristics of the multiple position extensometers in the microseismic event gathering area, this paper tries to establish the internal relation between the microseismic activity and the surrounding rock deformation during excavation of the underground powerhouse, explores the deformation mechanism of surrounding rock, and comprehensively analyzes the surrounding rock stability of the underground powerhouse $[2,19]$.

Figure 11 shows the arrangement of the two multiple position extensometers $\left(\mathrm{M}^{6} \mathrm{XZ}^{1-2}\right.$ and $\left.\mathrm{M}^{4}{ }_{\mathrm{CF}} 3-8\right)$ at elevations of $1705.35 \mathrm{~m}$ (stake: $0+34.00 \mathrm{~m}$ ) and $1706.50 \mathrm{~m}$ (stake: $0+$ $51.30 \mathrm{~m}$ ) between $1 \#$ and 3\# bus tunnels on the downstream side wall of the main powerhouse. 


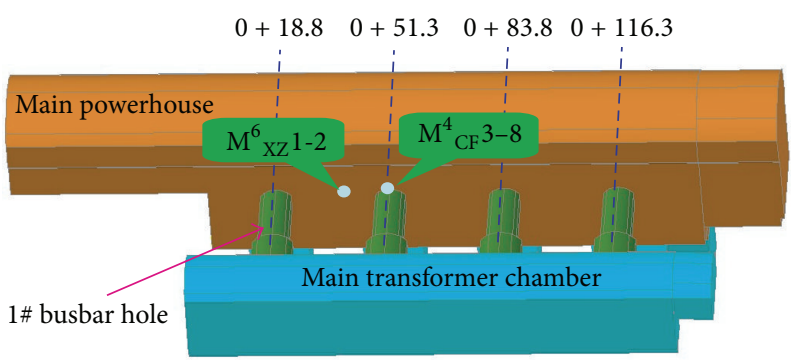

FIGURE 11: Arrangement of multiple position extensometers in microseismic events accumulative region.

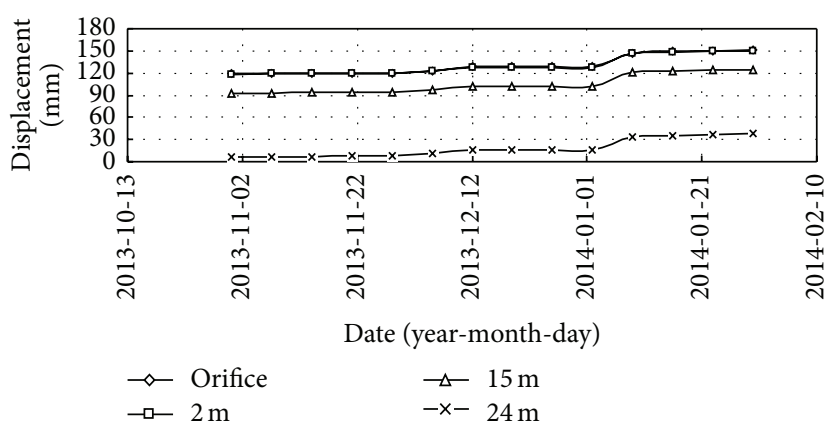

(a)

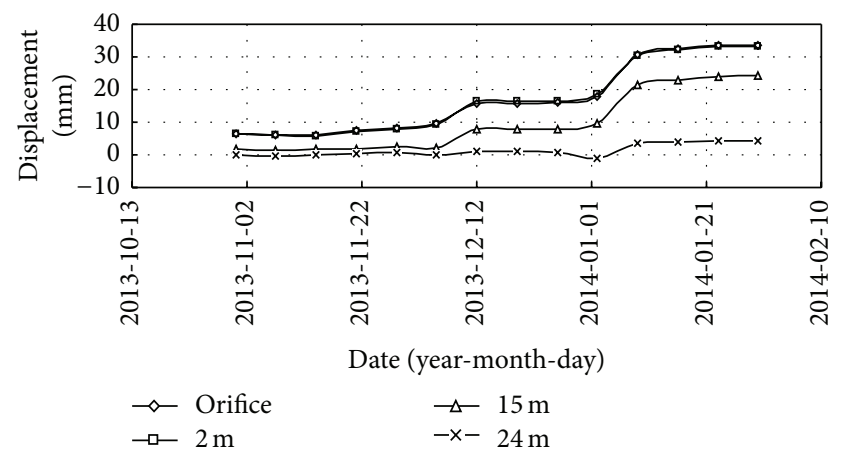

(b)

FIGURE 12: Curves of displacement change in microseismic events accumulative region. (a) Absolute displacement process of multiple position extensometers $\mathrm{M}^{6}{ }_{\mathrm{XZ}}{ }^{1-2}$. (b) Absolute displacement process of multiple position extensometers $\mathrm{M}_{\mathrm{CF}}^{4} 3-8$.

5.2. Relation between Surrounding Rock Deformation and Microseismic Activities. Figure 12 shows the absolute displacement change curves of multipoint displacement meters $\mathrm{M}^{6}{ }_{\mathrm{XZ}} 1-2$ and $\mathrm{M}_{\mathrm{CF}}^{4} 3-8$. It can be seen that surrounding rock in this area changed smoothly and deformations at each depth of monitoring points tended to converge before November 2013. From late December 2013 to early January 2014, $\mathrm{M}^{6}$ Xz $1-2$ showed about $10 \mathrm{~mm}$ and $15 \mathrm{~mm}$ deformations at the orifice and $\mathrm{M}_{\mathrm{CF}}^{4} 3-8$ also showed about $8 \mathrm{~mm}$ and $18 \mathrm{~mm}$ deformations at the orifice. Moreover, the deformation of deep rock within $15 \mathrm{~m}$ from the orifice increased obviously. Comprehensive analysis on the geological conditions, construction status, and deformation characteristics reveals that the deformation near the orifice was mainly dominated by tension after surrounding rock excavation unloading at large burial depth with high in situ stress. After the new surface is formed after excavation, the surrounding rocks between the main powerhouse and transformer chamber bear large vertical compressive stress; deep rock shows the shear failure along the fault direction; the area within $15 \mathrm{~m}$ shows large deformations [2].

Figure 13 shows the apparent stress change curve of microseismic events with time. The apparent stress refers to the stress releasing level at the hypocenter $[8,20]$. According to the quantitative seismology theory, the hypocenter stress is an important hypocenter parameter to measure seismic

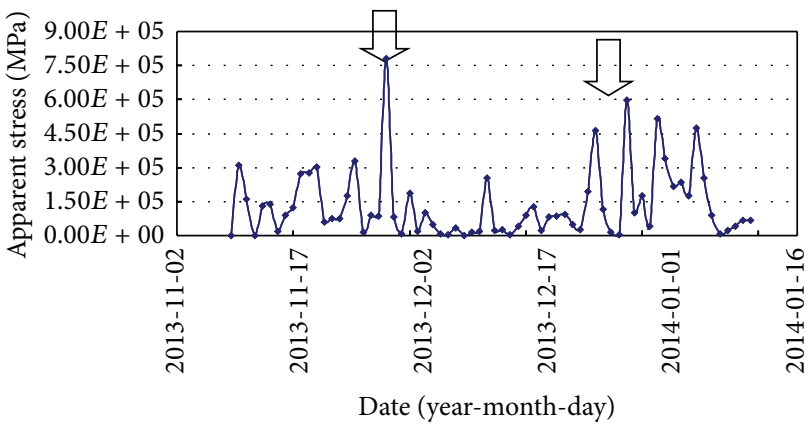

FIGURE 13: Curve of apparent stress change with time.

intensity. The apparent stress can be expressed by energy and seismic moment as

$$
\sigma_{A}=\frac{\mu E}{M_{0}} .
$$

In the preceding formula, $\sigma_{A}$ is the apparent stress; $\mu$ is the shear modulus; $E$ is the seismic energy; $M_{0}$ is the scalar seismic moment.

According to Figure 13, the apparent stress of microseismic events increases (indicated by the vertical arrow in the figure) before the two periods of surrounding rock 


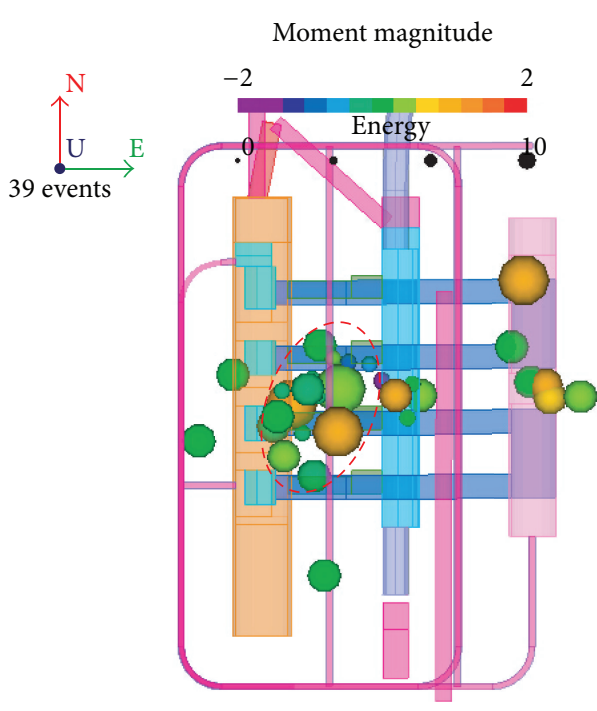

(a)

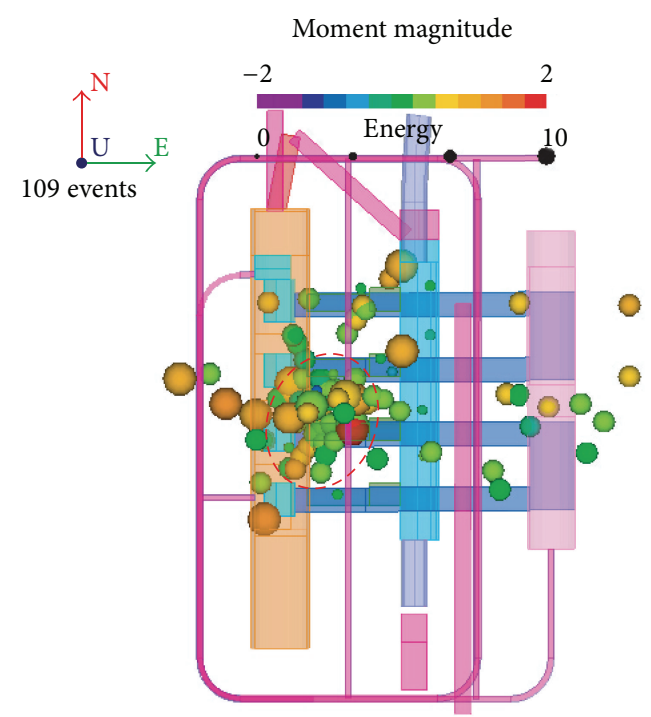

(b)

Figure 14: Spatial distribution of microseismic events in the deformation phases. (a) Period between November 25, 2013, and December 10, 2013. (b) Period between December 25, 2013, and January 10, 2014.

deformations and during the deformation period. Figure 14 shows the spatial distribution of microseismic events during the deformation period and a week before two deformations. It can be seen that microseismic events show obvious spatial aggregation before surrounding rock deforms and during the deformation period. Therefore, based on the spatial aggregation characteristics and apparent stress parameter changes of microseismic events, effective predictive analysis can be conducted on surrounding rock deformations in the underground powerhouse $[21,22]$.

\section{Conclusions}

Based on the space-time evolution of microseismic activities during excavation of the underground powerhouse of Houziyan hydropower station, the relationship between microseismic activity and blasting construction is established, and the potential instability areas of surrounding rock in the underground powerhouse are identified. The simulated deformation mechanism of the underground powerhouse is obtained, which reveals the correlation between surrounding rock deformation and microseismic activities. Some conclusions are drawn as follows.

(1) The number of microseismic events is closely related to blasting excavation of the main powerhouse. During the excavation period, microseismic events occur frequently and vice versa. During excavation of floors $\mathrm{V}$ and VI (EL. 1693 1680 m) of the main powerhouse, microseismic events mainly concentrate in the fault-controlled areas such as f1-1-3, fml, and fm4 between $1 \#$ and $3 \#$ bus tunnels, forming a band that is the potential instability and failure area revealed by microseismic events. Due to serious failure on deep surrounding rock, enhancing deep support measures and strictly controlling the explosive load and art for blasting are recommended.

(2) It is revealed that the excavation process of the typical section (stake: $0+70 \mathrm{~m}$ ) in the underground powerhouse is simulated and the largest surrounding rock deformation concentrates at the boundary of powerhouse floor and downstream sidewall and that the major deformation growth area locates near the fault. The deformation simulation results agree well with seismic deformations revealed by microseismic monitoring, indicating that faults and soft structural planes greatly affect the stability of the underground powerhouse subjected to excavation.

(3) The routine monitoring data indicates that the deformation in the gathering area of microseismic events during excavation of the main powerhouse shows two stepped growths and microseismic events gather in this area, accompanied with an increase in apparent stress before and during each deformation of surrounding rock. Therefore, the microseismic activity represents a precursor of surrounding rock deformation. The microseismic monitoring technology can thus be used to forecast the stability of surrounding rock subjected to excavation in underground engineering.

\section{Conflict of Interests}

The authors declare that there is no conflict of interests regarding the publication of this paper. 


\section{Acknowledgments}

The authors are grateful for the financial support from the National Program on Key basic Research Project (no. 2015CB057903), the National Natural Science Foundation of China (no. 51374149), the Program for New Century Excellent Talents in University of Ministry of Education of China (no. NCET-13-0382), China's Postdoctoral Science Foundation (no. 2013M540549), and the Youth Science and Technology Fund of Sichuan Province (2014JQ0004).

\section{References}

[1] C. Tang, J. Wang, and J. Zhang, "Preliminary engineering application of microseismic monitoring technique to rockburst prediction in tunneling of Jinping II project," Joumal of Rock Mechanics and Geotechnical Engineering, vol. 2010, no. 3, pp. 193-208, 2010.

[2] N.-W. Xu, C.-A. Tang, H. Li et al., "Excavation-induced microseismicity: microseismic monitoring and numerical simulation," Journal of Zhejiang University: Science A, vol. 13, no. 6, pp. 445-460, 2012.

[3] Q. X. Fan, Y. Y. Liu, and Y. Wang, "Construction and monitoring study of large underground powerhouse caverns of Xiangjiaba Hydropower Station," Chinese Journal of Rock Mechanics and Engineering, vol. 30, no. 4, pp. 666-676, 2011.

[4] N. W. Xu, C. A. Tang, L. C. Li et al., "Microseismic monitoring and stability analysis of the left bank slope in Jinping first stage hydropower station in southwestern China," International Journal of Rock Mechanics and Mining Sciences, vol. 48, no. 6, pp. 950-963, 2011.

[5] W. S. Zhu, B. Sui, X. J. Li, S. C. Li, and W. T. Wang, "A methodology for studying the high wall displacement of large scale underground cavern complexes and it's applications," Tunnelling and Underground Space Technology, vol. 23, no. 6, pp. 651-664, 2008.

[6] H. Yoshida and H. Horii, "Micromechanics-based continuum model for a jointed rock mass and excavation analyses of a large-scale cavern," International Journal of Rock Mechanics and Mining Sciences, vol. 41, no. 1, pp. 119-145, 2004.

[7] M. Yazdani, M. Sharifzadeh, K. Kamrani, and M. Ghorbani, "Displacement-based numerical back analysis for estimation of rock mass parameters in Siah Bisheh powerhouse cavern using continuum and discontinuum approach," Tunnelling and Underground Space Technology, vol. 28, no. 1, pp. 41-48, 2012.

[8] N. W. Xu, F. Dai, Z. Z. Liang, Z. Zhou, C. Sha, and C. A. Tang, "The dynamic evaluation of rock slope stability considering the effects of microseismic damage," Rock Mechanics and Rock Engineering, vol. 47, no. 2, pp. 621-642, 2014.

[9] N. W. Xu, C. A. Tang, H. Li, and Z. Z. Liang, "Application of microseismic monitoring technique in hydroelectric projects," in Hydropower-Practice and Application, pp. 143-167, InTech, Rijeka, Croatia, 2012.

[10] B.-R. Chen, X.-T. Feng, Q.-P. Li, R.-Z. Luo, and S. Li, "ock burst intensity classification based on the radiated energy with damage intensity at Jinping II hydropower station, China," Rock Mechanics and Rock Engineering, vol. 48, no. 1, pp. 289-303, 2015.

[11] B. H. Zhang, J. H. Deng, and M. Z. Gao, "Safety evaluation research based on microseismic monitoring in underground powerhouse of hydropower station," Chinese Journal of Rock Mechanics and Engineering, vol. 31, no. 5, pp. 937-944, 2012.
[12] B. Li, F. Dai, N. Xu et al., "Microseismic monitoring system and its engineering applications of deep-buried underground powerhouse," Chinese Journal of Rock Mechanics and Engineering, vol. 33, no. 1, pp. 3375-3383, 2014.

[13] B. R. Chen, G. L. Feng, and Q. P. Li, "Analysis of micorseismic charicteristic and rockburst risk during TBM excavation under deeply buried tunnel," Disaster Advances, vol. 6, supplement 1, pp. 122-128, 2013.

[14] W. Lu and W. Hustrulid, "A further study on the mechanism of airdecking," Fragblast: The International Journal for Blasting and Fragmentation, vol. 7, no. 4, pp. 231-255, 2003.

[15] M. Tezuka and T. Seoka, "Latest technology of underground rock cavern excavation in Japan," Tunnelling and Underground Space Technology, vol. 18, no. 2-3, pp. 127-144, 2003.

[16] F. Q. Wu, X. H. Hu, M. F. Gong, J. Y. Liu, and A. W. Ren, "Unloading deformation during layered excavation for the underground powerhouse of Jinping I Hydropower Station, Southwest China," Bulletin of Engineering Geology and the Environment, vol. 69, no. 3, pp. 343-351, 2010.

[17] M. Cai, P. K. Kaiser, H. Morioka et al., "FLAC/PFC coupled numerical simulation of AE in large-scale underground excavations," International Journal of Rock Mechanics and Mining Sciences, vol. 44, no. 4, pp. 550-564, 2007.

[18] D. P. Zhu, E. C. Yan, G. X. Hu, and Y. D. Lin, "Revival deformation mechanism of Hefeng landslide in the three gorges reservoir based on FLAC3D software," Procedia Engineering, vol. 15, pp. 2847-2851, 2011.

[19] K. Ma, C.-A. Tang, N.-W. Xu, F. Liu, and J.-W. Xu, "Failure precursor of surrounding rock mass around cross tunnel in high-steep rock slope," Journal of Central South University, vol. 20, no. 1, pp. 207-217, 2013.

[20] M. Wyss and J. N. Brune, "Seismic moment, stress, and source dimensions for earthquakes in the California-Nevada region," Journal of Geophysical Research, vol. 73, no. 14, pp. 4681-4694, 1968.

[21] N. W. Xu, C.-A. Tang, H. Li, and S. H. Wu, "Optimal design of microseismic monitoring networking and error analysis of seismic source location for rock slope," Open Civil Engineering Journal, vol. 5, no. 1, pp. 36-45, 2011.

[22] N. Xu, T. Li, F. Dai, B. Li, Y. Zhu, and D. Yang, "Microseismic monitoring and stability evaluation for the large scale underground caverns at the Houziyan hydropower station in Southwest China," Engineering Geology, vol. 188, pp. 48-67, 2015. 

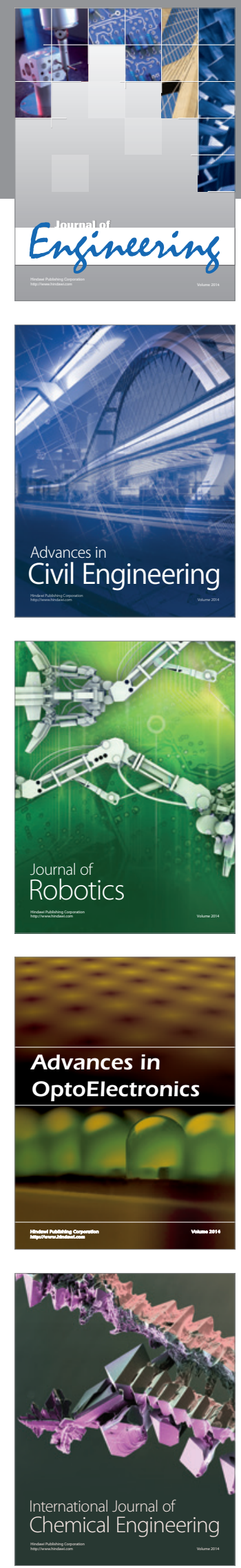

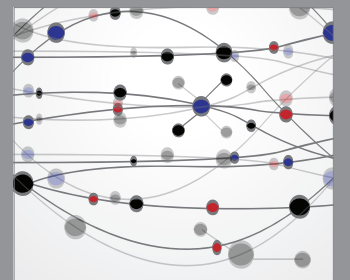

The Scientific World Journal
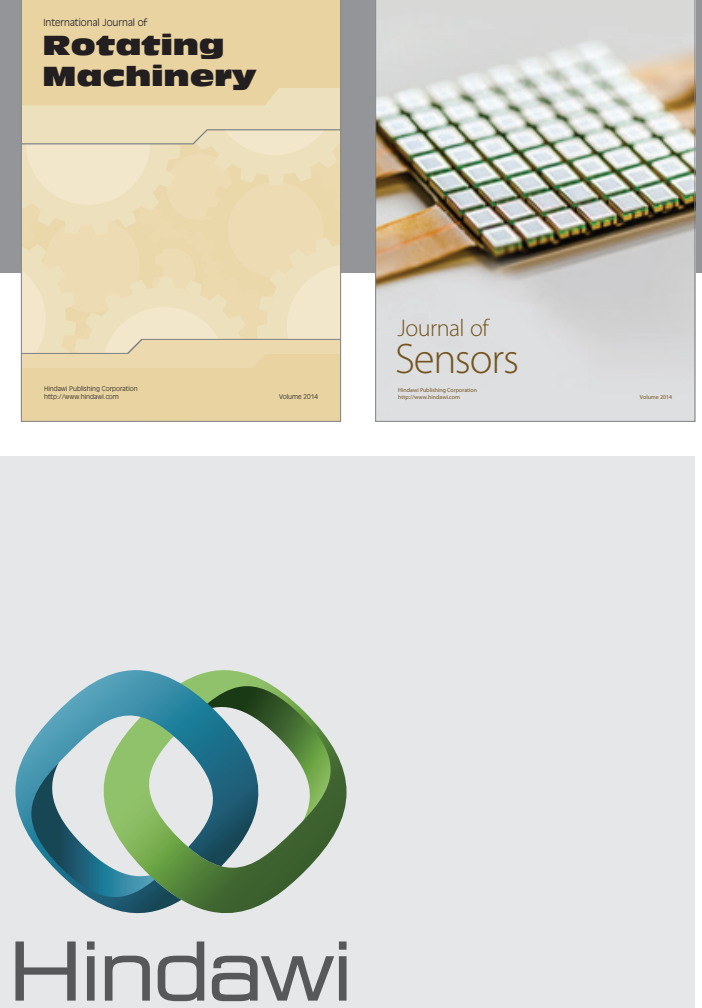

Submit your manuscripts at http://www.hindawi.com
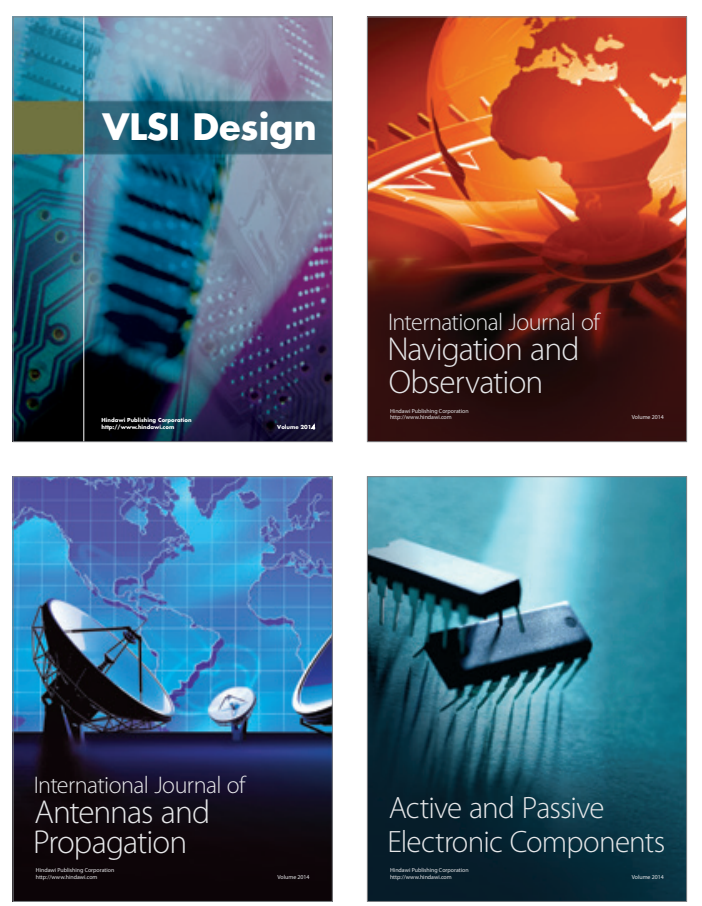
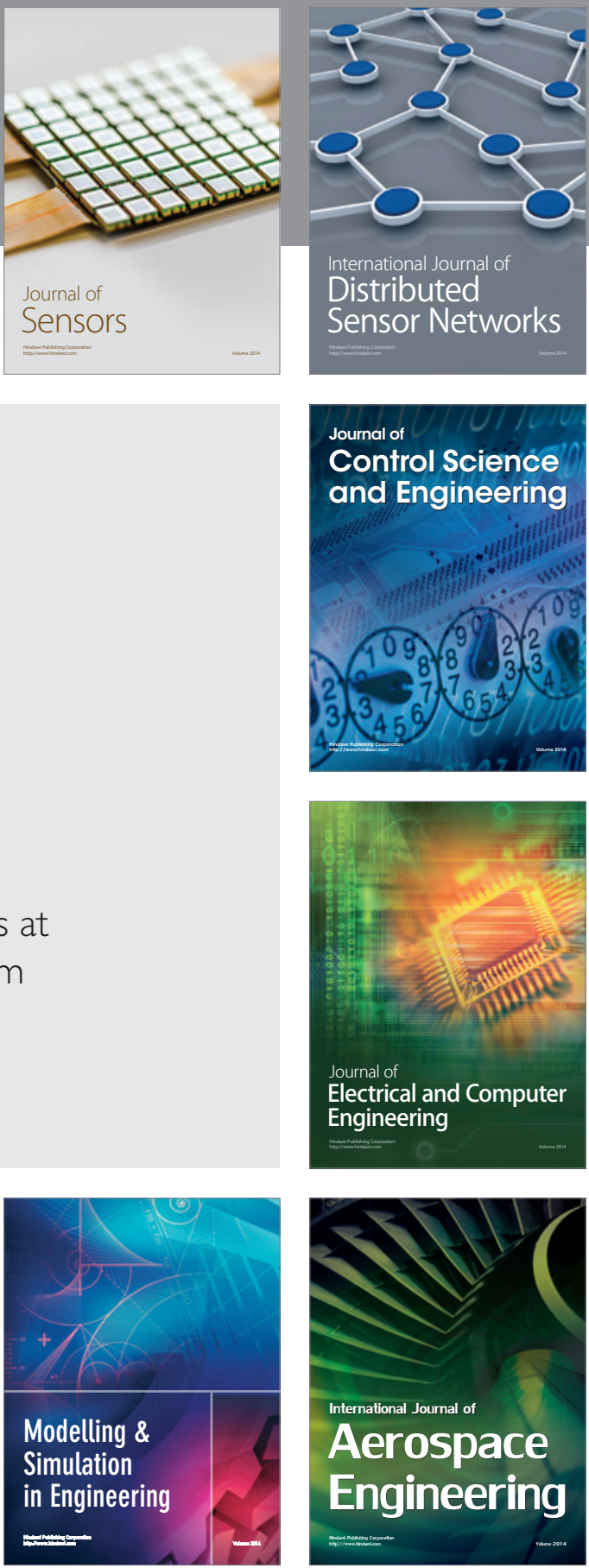

Journal of

Control Science

and Engineering
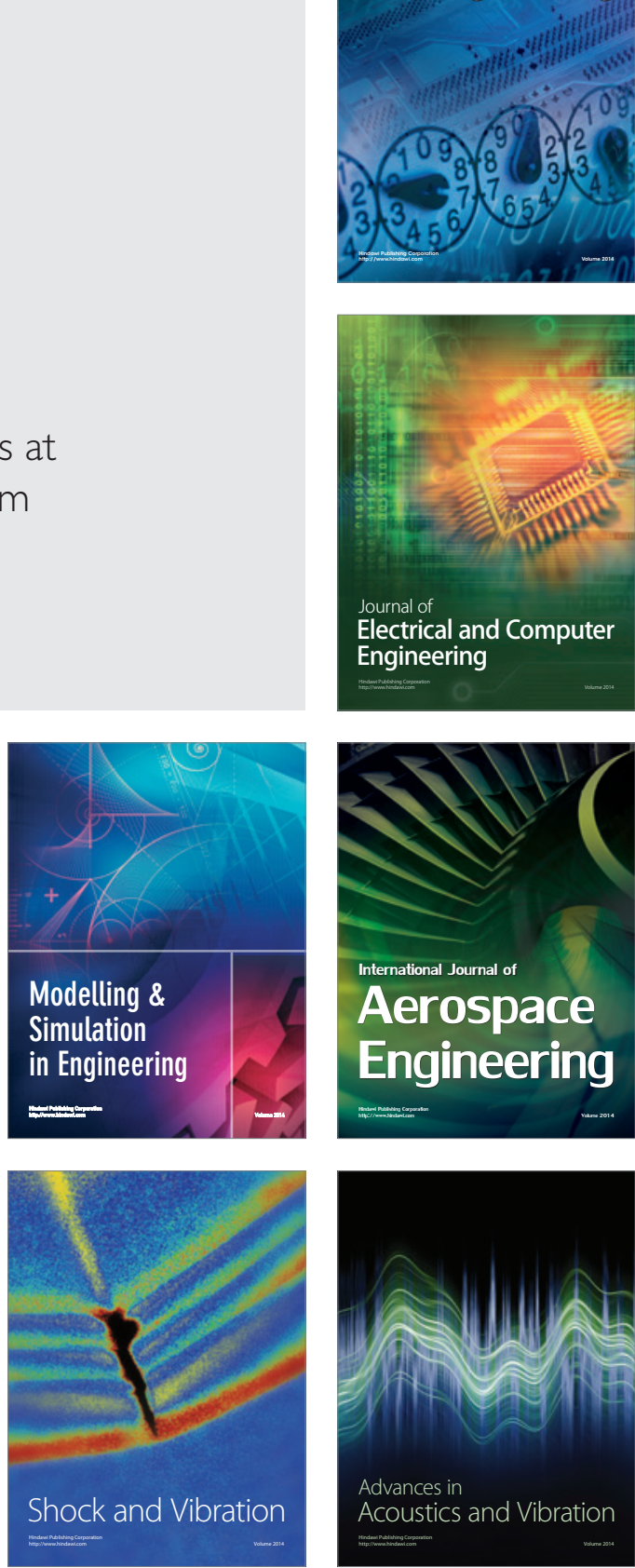